\section{Clonidin-Test (Suppressionstest)}

\section{W. Hubl}

Ehem. Krankenhaus Dresden-Friedrichstadt, Institut für Klinische Chemie und Labormedizin, Dresden, Deutschland

\section{Synonym(e) Clonidin-Suppressionstest}

Englischer Begriff clonidine test; clonidine suppression test

Definition Clonidin hemmt als $\alpha$-adrenerger Agonist die Katecholamin-Sekretion bei gesunden Personen. Bei Vorliegen eines Phäochromozytoms mit autonomer Katecholaminsekretion wird kein Abfall der Plasmakatecholamine oder Plasmametanephrine erzielt.

\section{Durchführung}

- Möglichst mindestens 24 Stunden vor Beginn sollte eine antihypertensive Therapie, außer Calciumantagonisten, abgesetzt werden

- Legen einer Venenkanüle, Patient 30 Minuten in liegender Körperhaltung

- Blutentnahme zur Bestimmung von Adrenalin und Noradrenalin (Basiswerte)

- Gabe von $300 \mu \mathrm{g}$ Clonidin (Catapresan) oral

- Nach 180 Minuten zweite Blutentnahme für die Bestimmung von Adrenalin und Noradrenalin bzw. der Metanephrine im Serum

- Der Test ist unter ständiger Blutdruckkontrolle (in 30Minuten-Abständen) durchzuführen.

Untersuchungsmaterial - Entnahmebedingungen $>\mathrm{Ka}$ techolamine.
Präanalytik $>$ Katecholamine.

Analytik Katecholamine.

Referenzbereich - Erwachsene Abfall von Adrenalin und/ oder Noradrenalin bzw. der Metanephrine auf mindestens $50 \%$ des Ausgangswerts.

Indikation Verdacht auf eine autonome Adrenalin- oder Noradrenalinproduktion (Phäochromozytom). Kein Suchtest, sondern ein Bestätigungstest für ein Phäochromozytom nach pathologischen oder grenzwertigen Katecholamin- bzw. Metanephrinwerten.

Kontraindikation(en) Bradykarde Herzrhythmusstörungen.

Nebenwirkung(en) Bei Phäochromozytom-Patienten hypertensive Krisen, bei Gesunden Hypotonie.

Interpretation Ein ausbleibender oder geringerer Abfall von Noradrenalin (bzw. Adrenalin) auf weniger als $50 \%$ des erhöhten Ausgangswerts deutet auf ein Phäochromozytom hin.

Diagnostische Wertigkeit Diagnostische Sensitivität $87 \%$, diagnostische Spezifität $93 \%$.

\section{Literatur}

Schäffler A (Hrsg) (2015) Funktionsdiagnostik in Endokrinologie, Diabetologie und Stoffwechsel. Indikation, Testvorbereitung und -durchführung, Interpretation. Springer/GmbH \& Co. K, Berlin/Heidelberg

Thomas L (Hrsg) (2012) Labor und Diagnose : Indikation und Bewertung von Laborbefunden für die medizinische Diagnostik, 8. Aufl. Th-Books, Frankfurt am Main

Probenstabilität $>$ Katecholamine. 